\title{
TOWARDS A FRAMEWORK FOR CONCEPTUAL MODEL HYBRIDIZATION IN HEALTHCARE
}

\author{
Jafri Zulkepli \\ School of Quantitative Sciences \\ College of Arts \& Sciences \\ Universiti Utara Malaysia \\ Sintok, Kedah, 06010, MALAYSIA
}

Tillal Eldabi

\author{
Brunel Business School \\ Brunel University London \\ Eastern Gateway Building \\ Uxbridge, Middx, UB8 3PH, UK
}

\begin{abstract}
It is well documented that modeling large complex healthcare systems cannot be achieved using the traditional single-technique approach. Developing large healthcare models requires more than one way of thinking about it, as healthcare systems consist of multiple stakeholders, policies, types of patients and many more complex subsidiaries. Whilst the literature is abound with hybrid models and attempts to theorize multi-method approaches, there is limited guidance of how to go about building a hybrid model and when. In this paper we attempt to develop a guiding framework focusing identifying what issues to consider when building a hybrid model. This 3-phased framework is based on model decomposition into modules, assigning methods to these modules, and identification of communication strategies between them. We start our endeavor by focusing on two types of popular techniques, namely system dynamics and discrete event simulation.
\end{abstract}

\section{INTRODUCTION}

Hybrid simulation is not a novel concept anymore, especially when it comes to combining Discrete Event Simulation (DES) and System Dynamics (SD). There are many hybrid models developed and used in various areas such as in manufacturing, software development, supply chain, construction and healthcare (Martin and Raffo 2000; Rabelo et al. 2003; Helal et al. 2007; Venkateswaran et al. 2006; Lee at al.; 2007; Chahal et al., 2009). Particularly, in healthcare, there is a growing body of literature which is presented in Viana (2014) and Brailsford (2014). Most of these hybrid simulation models were developed on ad hoc technical basis, focusing mainly on the software connectivity between two or more techniques (e.g. DES and SD). However, the unique nature of healthcare systems requires modelers to move from the ad hoc hybridization of models to a more conceptual hybridization to aid nonexperts in developing hybrid simulation models and in the same time save time later. In this regard, we argue that it would perhaps be more beneficial to develop a guiding framework that facilitates the model development process starting at the conceptual phase, particularly when a hybrid simulation is needed. This idea is supported by Lynch et al (2014), Balaban (2014) and Brailsford (2014). Such a framework will also be useful to ensure that the developed model would communicate in a more efficient way (Mingers and Brocklesby 1997). Therefore, this paper proposes a guiding framework for hybrid simulation at the conceptual level - or at least before starting a process of a complex hybrid software development. The authors hope that this framework would support modeling large healthcare systems. 


\section{BACKGROUND TO HYBRID DES/SD MODELS}

There are many simulation techniques and methods, which vary depending on the type of problem being modeled and the expertise of the modeler(s). also there are many forms of hybrid simulation models, however in this paper are focusing on hybridization of Discrete Event Simulation (DES) and Systems Dynamics (SD) techniques. It was suggested by Brailsford (2008) that, although the result would be beneficial, combining DES and SD techniques can be quite challenging, especially in the healthcare sector, since the detailed individual analysis (provided by DES) and the whole system capture (by SD) require different conceptual approaches. These two simulation branches have a common basis, but efforts to combine them were met with many challenges (Sweester 1999, Lane 2000, Brailsford and Hilton 2001, Moorcroft and Robinson 2005). However, the movement to combine them started to gather momentum in recent years. Chahal (2009) provides an extensive review of several applications and frameworks for hybrid simulation especially DES with SD, which are applied in various field, for example, software development, manufacturing, supply chain, and construction (Christie and Staley 2000; Martin and Raffo 2000; Setamanit et al. 2007). More recently, we find that a number of hybrid models were developed in the healthcare arena. For example, Revetria et al. (2012) developed a generic model for complex healthcare operations, a similar case was examined by Zulkepli et al. (2012), who developed a hybrid framework of modeling complex patient pathways using SD and DES. Using Anylogic software, Ahmad et al. (2012) developed a hybrid model of an emergency department in Malaysia. In term of disease, Viana et al. (2014) developed a hybrid model to examine the infection process of chlamydia in outpatient clinics. Most of the aforementioned attempts were heavily reliant on the expertise (and the will) of the modelers to develop hybrid models with no standardized process. In the following section we explore the initial attempts to develop generic frameworks for non-experts.

\section{HYBRID FRAMEWORKS}

As mentioned by Robinson (2008), conceptual modeling is the most important and vital aspect in simulation modeling. Conceptual modeling refer to the abstracting of a model from a real or a proposed system, from problem situation to a definition of what is going to be modeled and how, depending on model requirements. Robinson (2008) argued that the conceptual model should provide a specific set of steps that will guide modeler on how to translate model into existence. The same is true for hybrid modeling where most of the current attempts are focused more on the software level with less emphasis on the conceptual level. In this section we present three frameworks for hybrid modeling that aimed at improving the process at the conceptual modeling.

Firstly, Chahal (2009) developed a generic framework for hybrid simulation techniques in healthcare as a result of analysis of previous studies concerning existing hybrid simulation applications and frameworks. Basically, the overall framework has been subdivided into three major phases (problem identification; mapping between DES and SD; and identification of mode of interaction). The whole generic framework can be found in Chahal and Eldabi (2008) whilst the applications can be found in Chahal et al. (2009). However, in large healthcare systems such as integrated care, it can be said that this framework needed some improvements. Chahal's framework is only suitable as a guideline for a single system. Although the framework provides guidelines on simulation techniques for modeling by dividing the main objective to several objectives, we argue that this method was too subjective and the authors did not provide guidelines on how to decompose the main objective to several objectives - when is appropriate for simplifying the model. To model a large system that has different sub-objectives may require an extensive work in dividing the overall objectives. This is the main reason we feel that Chahal's framework was only suitable for the single system, rather than complex and have multiple departments, such as integrated care. Most importantly, Chahal's framework 


\section{Zulkepli and Eldabi}

was not did not provide any guideline on what and how the information between both models were exchanged and how to stop the process.

Helal et al. (2007) introduced a methodology that could integrate and synchronize the DES and SD applications in an integrated manufacturing enterprise. The framework is based on the modular concept where the modeled system would be decomposed into several smaller modules for modeling purposes. These modules (whether SD and DES based) are formalized and synchronized using the SDDES controller. The actual SD and DES models were synchronized using the time bucket (TB) synchronizing method. However, as argued by Chahal (2009), Helal et al. (2007) framework does not select which problem is can be modeled using DES or SD, separately in a hybrid fashion. The underlining assumption is that all modules are built for hybrid simulation, which sometimes could be unnecessary. For example, in this case SD alone is more appropriate. Furthermore, we argue that the framework of Helal et al. (2007) is too technical and not easy to understand, especially in terms of their hybrid 'operation'.

Another framework that used DES and SD simultaneously was developed by Giachetti et al. (2005) for an outpatient clinic simulation model to assess the viability of an open access policy. The authors used DES to analyze the patient's cycle time and suggested an improvement, whilst the SD was used to analyze the patient's behavior and factors that lead to the high no-show rate. Based on the DES simulation, several recommendations were suggested by the authors in terms of discharging patients, patient appointment scheduling, service providers and order in which the patient should be called. The framework used SD to capture the feedback loops. Analysis of the framework suggested that the lack of consideration of what to approach to select before indulging in the hybridization process, has a significant impact on the success or efficiency of the overall process.

\section{A FRAMEWORK FOR MODELING LARGE HEALTHCARE MODEL USING HYBRID SIMULATION}

Two main lessons are drawn from the above discussion: firstly, existing hybridization frameworks are have the capability to guide modelers to develop hybrid models, however, more is needed in terms of selection and identification in the earlier phases; secondly, it would be beneficial - to improve the efficacy of such frameworks - to understand the nature of communication between the hybridized models at the conceptual stage. In trying to meet these lessons, we propose a 3-phase framework that adds selection and communication elements as part of a series of guiding steps for developing the hybrid models. The three phases of the framework are: the conceptual phase; the modeling phase; and the model communication phase. The conceptual phase is concerned with translating the logical model into more descriptive model (building block). The modeling phase is concerned with translating the conceptual model into simulation models using any modeling and simulation tools. The challenging task in this framework is how to design and perform the hybrid process between two different techniques and software. This can be reviewed when linking different software which is outside the scope of this paper. The final stage is concerned with models' communication, whereas, the information between variables in both models is mutually exchangeable. The most important issue here is the ability to identify one or more components from one model that are influencing (or influenced by) one or more components from another model, regardless of which is SD or DES model. The following subsections provide more details about the framework and its three phases.

\subsection{Phase 1: Conceptual Phase}

The objective of the first phase in this framework is to develop a set of conceptual modules that represent the problem to be modeled. The basic assumption is that these modules cannot be divided into smaller chunks whilst together they are able to represent the system. Generally, the conceptual phase helps modelers and the stakeholders to view the system as a whole as well as a collection 


\section{Zulkepli and Eldabi}

of interrelated modules. There are six steps in this phase. Figure 1 depicts these steps, which are detailed below:

Step one is 'Problem Source Definition and Objective(s) Identification'. This step helps the modelers in defining the boundaries of the system and focus more on the components that lead to the modeling process. This activity is performed by collecting the information from the stakeholders involved in the system. This step also includes defining the problem where issues are vague and unclear, which adds to the complexity (Eldabi 1999). The process of collecting all the information from the stakeholders will ensure that the modelers will focus more on the root of the problem rather than the symptoms. This step also helps in facilitating the identification of the objective, which will identify the boundaries of the model (Pressman 1997) and, consequently, save time and other resources for model development.

The second step is the 'conceptual model and modularization process.' It is a well-established fact that the conceptual model allows the modelers to develop their vision of the system so it can be translated into a runnable software model later. As far as the proposed framework is concerned, the conceptual model development is followed by the modularization process, which aims at subdividing the conceptual model into several modules, each contains one or more processes/activities (Pressman, 1997). Subdividing the model into several processes could be based on the care settings (e.g. healthcare, social care, A\&E, surgery, outpatient, etc.) or by dividing long patient pathways into modules. The purpose of modularization is for developing the DES model, as it will simplify the complex model. As for SD, although it is used for modeling the whole system, if the system is too complex, the modeler may reduce such complexity by divided it into smaller units. However, this is rarely the case due to the objective of the SD model.

The third step is to 'identify affected modules.' The affected module(s) is/are ultimately identified based on the objectives of model. This will assist in defining boundaries of the model and, consequently, reduces the model development time. The selection process depends on the professionals and stakeholders involved in the decision making activities.

Step Four, 'identification of the characteristics of each module'. Identifying the characteristics of the modules helps the modelers decide which technique(s) is/are suitable for modeling each specified module. Such characteristics are: short- (or long) term effect; type of analysis (individual or aggregate), feedback requirement etc. To perform this activity, a set of questions were developed as follows:

a. To determine whether the module is affected long- or short-term - e.g. will the intervention affect the other subsystems in the short- or/as well as the long-term?

b. To determine what type of analysis should be performed in each module. This is decided based on the granularity and variations of the values within the variables (e.g. time/patient's type of disease). For example, if the values vary significantly then individual analysis maybe required. If, on the other hand, there is no significant variation then more aggregate analysis maybe required for the particular module.

c. To determine whether the module has a feedback loop or not -i.e. will any interventions/actions cause backward feedback (to previous module/steps)?

The modelers may seek expert opinion to help in determining the characteristics of each module. This step will continue until all modules have been identified by their variables and characteristics.

Step Six is to 'identify the suitable technique for modeling' each of the module. The modeling technique(s) assigned in this step will depend on the previous step. That is DES will be used for modeling short-term effects and individual analysis, whilst SD will be used for capturing long-term effects as well as aggregate analysis and feedback loops. A hybrid simulation will be required if the variables are a mixture of both. 


\section{Zulkepli and Eldabi}

The last step is the 'modeling plan', that is to finalize what technique would be used for modeling each module and how detailed each module should be, especially when the SD technique is required. This step controls the modeling activity in the next phase of this framework. There are six possible modeling plans, which are categorized into three main categories. These are:

a. All modules use a single technique - either SD or DES technique.

b. Some module(s) use a single technique, whilst some use the hybrid - SD + hybrid or DES + hybrid.

c. All modules have to use the hybrid simulation.

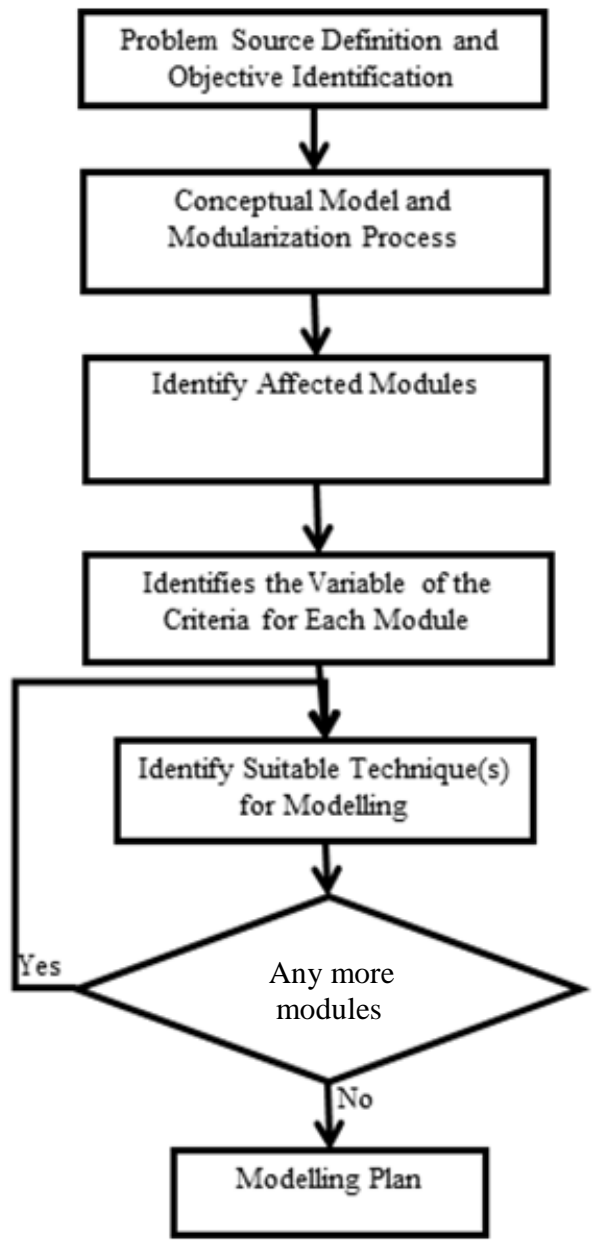

Figure 1: Conceptual phase in the framework.

\subsection{Phase 2: Modeling Phase}

The second phase in the framework is the modeling phase, which is depicted in Figure 2. The SD and DES models can be developed simultaneously if expertise is available. The development of the DES/DS models are based on the previous step (each module is developed using DES, SD or both). As we mentioned earlier on this paper, this guidelines/framework is aimed at non-technical modeler developer. The practical aspect of the modeling will be based on the plan defined in the previous phase. The translation of the conceptual model into a software package starts by building the DES modules 


\section{Zulkepli and Eldabi}

sequentially, using any DES commercial package. These modules will be linked using their outputs i.e. output from one module will serve as input to the next module and so on. The variables involved in this process are mainly, but not necessarily restricted to, patients' information, such as the time taken to complete a certain task and personal information if needed (age, type of illness, sex, etc.). The SD modules will be applied on a module-by-module basis and will link the modules by connecting the stocks and flows or their auxiliaries using any SD commercial packages. The detailed and more rigorous part of the modules in the SD modeling will be conducted depending on the modeling plan that has been identified in the conceptual model.

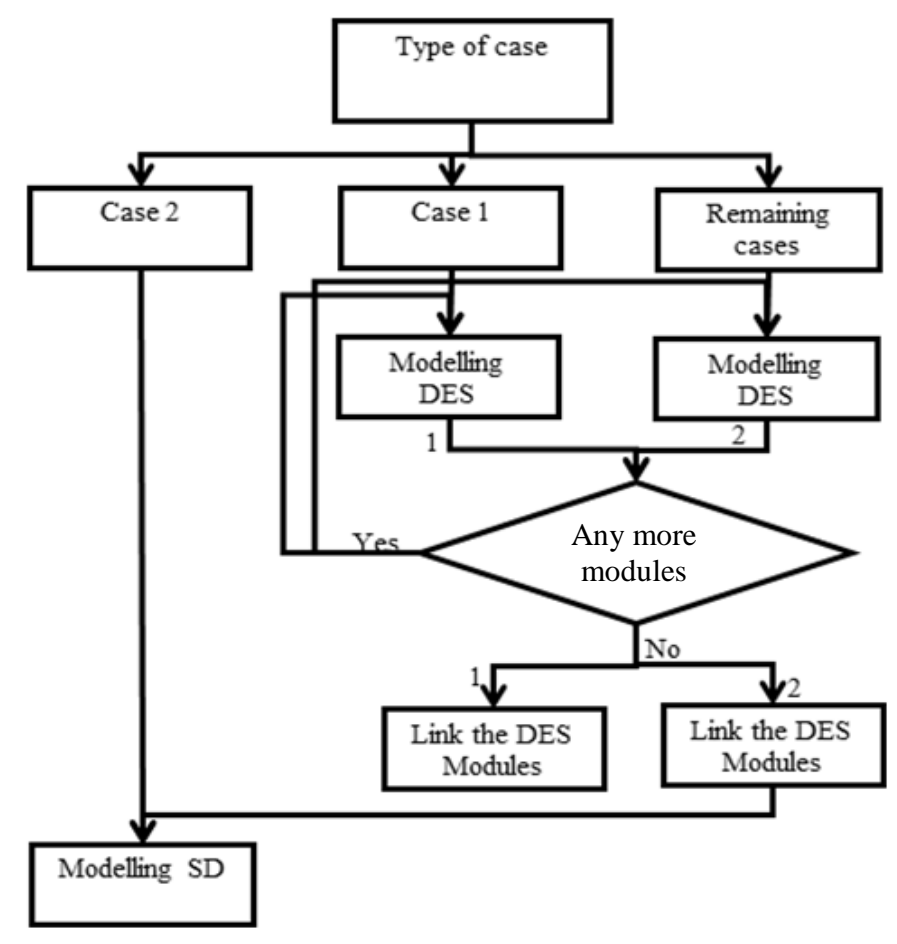

Figure 2: Modeling phase in the framework.

\subsection{Phase 3: Models Communication Phase}

Phase 3 of the framework is about defining the communication plans between the different modules. We use the term "communication" in this phase as it is about identifying how variables from some models communicate and change their impact on other variables in other model, e.g. a variable from DES to SD and vice versa. The 'communication' also encapsulate how both models are changing their outputs. The linkage between models is decided by identifying the 'influencing' and the 'influenced' variables that make these models "communicate" with each other. Prior to this phase, the modeler should determine whether the models can be integrated or not, and identify the variables from one model that will influence other variables in the other model (Chahal 2009). This phase determines how the communication between both models takes place. The following discussion provides the explanation of the six steps involved in this phase, whilst the flow of this phase is depicted in Figure 3.

The first step in this phase is 'identifying the variables in both models that can be linked together'. The identification of such variables is done by detecting all the variables that 'influence' or 'influenced' in both models. Expert opinion can be sought to validate which variables can be considered as 'influence' variables and which are 'influenced' variables. Table 1 presents several potential variables that are involved in modeling the healthcare system. The linkages for these variables were taken from 


\section{Zulkepli and Eldabi}

the literature and validated by expert opinions. These variables are divided into two types ('influence' and 'influenced') coupled with their relevant techniques (SD/DES). It is worth noting that the techniques used to model these variables may also depend on the modelers' expertise. The key to selecting which technique to use depend on the type of variable.

Table 1: Example of variable 'influence' and 'influenced'.

\begin{tabular}{|c|c|c|c|c|}
\hline \multirow{2}{*}{\multicolumn{2}{|c|}{$\begin{array}{l}\text { Variable Influencing } \\
\text { Suitable Captured by: }\end{array}$}} & \multirow{2}{*}{\multicolumn{2}{|c|}{$\begin{array}{l}\text { Variable 'Influenced by' } \\
\text { Suitable Captured by: }\end{array}$}} & \multirow[t]{3}{*}{ References } \\
\hline & & & & \\
\hline DES & SD & DES & SD & \\
\hline \multirow[t]{2}{*}{$\begin{array}{l}\text { Total patients } \\
\text { (workload) }\end{array}$} & & $\begin{array}{l}\text { Time: waiting and } \\
\text { finished in the } \\
\text { system } \\
\text { Patients: } \\
\text { waiting }\end{array}$ & $\begin{array}{l}\text { Professional: } \\
\text { performance, } \\
\text { motivation, } \\
\text { pressure } \\
\text { Patient: fatigue, } \\
\text { bored }\end{array}$ & $\begin{array}{l}\text { Pauliakas and } \\
\text { Theodossiou } \\
\text { (2009)' Pfeffer } \\
\text { and Langton } \\
\text { (1993), } \\
\text { Expert Opinion }\end{array}$ \\
\hline & $\begin{array}{l}\text { Professionals' } \\
\text { Knowledge and } \\
\text { experiences; } \\
\text { Motivation, } \\
\text { performance }\end{array}$ & $\begin{array}{l}\text { Time: waiting and } \\
\text { finish time in the } \\
\text { system, } \\
\text { Total patients finish } \\
\text { within time frame }\end{array}$ & $\begin{array}{l}\text { Performance and } \\
\text { motivation, } \\
\text { assessment of the } \\
\text { patients health; } \\
\text { Quality in patient } \\
\text { assessment; job } \\
\text { satisfaction }\end{array}$ & $\begin{array}{l}\text { Chahal and } \\
\text { Eldabi (2009)' } \\
\text { Heywood and } \\
\text { Wei (2006) }\end{array}$ \\
\hline $\begin{array}{l}\text { Incentives, } \\
\text { compensation }\end{array}$ & & & $\begin{array}{l}\text { Performance and } \\
\text { motivation }\end{array}$ & $\begin{array}{l}\text { McCausland et } \\
\text { al. (2005), } \\
\text { Pauliakas and } \\
\text { Theodossiou } \\
(2009) \text {, James } \\
(2005)\end{array}$ \\
\hline \begin{tabular}{lr}
\multicolumn{2}{l}{ Total professionals } \\
working; & other \\
resources; & spaces; \\
facilities
\end{tabular} & & $\begin{array}{l}\text { Waiting time, total } \\
\text { patient finished in } \\
\text { the system, demand }\end{array}$ & $\begin{array}{l}\text { Professional: } \\
\text { performance, } \\
\text { motivation, } \\
\text { pressure, quality in } \\
\text { patient assessment; } \\
\text { Quality of the } \\
\text { patient's health }\end{array}$ & $\begin{array}{l}\text { Pauliakas and } \\
\text { Theodossiou } \\
\text { (2009), Pfeffer } \\
\text { Langton } \\
\text { (1993), Elf and } \\
\text { Putilova } \\
\text { (2005), Bird et } \\
\text { al. (2007), } \\
\text { Ulrich, (1991) }\end{array}$ \\
\hline \multirow[t]{2}{*}{$\begin{array}{l}\text { Time frame (e.g. } 4 \\
\text { hours for treating } \\
\text { patient) }\end{array}$} & & & $\begin{array}{l}\text { Pressure, } \\
\text { performance; } \\
\text { Patient emotion } \\
\text { (fatigue and bored) }\end{array}$ & $\begin{array}{l}\text { Chahal and } \\
\text { Eldabi (2009), } \\
\text { expert opinion }\end{array}$ \\
\hline & $\begin{array}{l}\text { Pressure/stress of } \\
\text { the professionals }\end{array}$ & & $\begin{array}{l}\text { Quality of the } \\
\text { patient assessment }\end{array}$ & $\begin{array}{l}\text { Aiken et al. } \\
(2002)\end{array}$ \\
\hline $\begin{array}{l}\text { Total patient } \\
\text { readmission }\end{array}$ & & & $\begin{array}{l}\text { Distance from } \\
\text { home to hospital } \\
\text { as they hard to } \\
\text { get the treatment }\end{array}$ & $\begin{array}{l}\text { Dellasega et al. } \\
\text { (1999) }\end{array}$ \\
\hline
\end{tabular}


Zulkepli and Eldabi

\begin{tabular}{|l|l|l|l|l|}
\hline Treatment time & & $\begin{array}{l}\text { Quality } \\
\text { Assessment }\end{array}$ & $\begin{array}{l}\text { Patient's } \\
\text { Satisfaction }\end{array}$ & $\begin{array}{l}\text { McCausland et } \\
\text { al. (2005) }\end{array}$ \\
\hline & $\begin{array}{l}\text { Quality of } \\
\text { assessment }\end{array}$ & & $\begin{array}{l}\text { Patient's } \\
\text { Satisfaction }\end{array}$ & $\begin{array}{l}\text { Aiken et al. } \\
(1998)\end{array}$ \\
\hline
\end{tabular}

The second step is to 'define the last output from the linkage variable'. Based on the previous linkage variables, the new output will be produced, which may or may not influence other variables depending on the model. For example, the total number of patients will influence the performance of the professionals, consequently, this may result in a mistaken assessment due to pressure. In this case, the linkage variables are the number of patients and performance, whilst the last output is patient assessment.

As there could be many variables that can be linked between the models, the modeler should define the initial influencing variable. Therefore, the next step is to 'identify the initial influencing variable'. This also helps the modeler in deciding which model should be run first. Chahal (2009) introduced two types of interaction, or model communication, for now we will be focusing on cyclic interaction for the framework development. It would be impractical to test 'parallel' interaction whilst manually transferring data. Parallel interaction may require more custom programming to be used as an agent that will facilitate the models interactions.

Step Four is: 'model execution and data exchange'. The 'variables involved' are those identified in Step One as 'influence' or 'influenced' variables. This step will be performed twice at most, as it might go into a loop, especially when both modules have initial influencing variables. As both the SD and DES models may have an initial influencing variable, we will use the 'source model' as the general term in this framework to define the model with the initial 'influencing' variable(s), whilst the 'destination model' contains the initial 'influenced' variable(s). The process of running and transferring data between both models carry on until either of the following occur, the 'influenced' variable is not influenced by any other variables, or outputs from both models reached a stable situation, i.e. not much difference but the output of the different processes.

Step Five is the 'evaluation of the outputs'. The final output can be from either the 'source' or the 'destination' model. That is the final output will be from the destination model unless that there are some variables in the source model which are influenced by the variables in the destination mode. In such case the final output will be traced from the destination model.

The last step of this phase is 'suggestions for improvements'. One of the advantages of the simulation method that can be used for experimentation is that several interventions can be performed by the modeler to select the best intervention for system improvements. Basically, to maintain the relationship between both models, changing of input should be performed in both models. However, there are certain situations where only the input/variable of a particular model should be changed. Figure 3 depicts the final phase of this framework. They are some steps that we have decomposed into several steps (small box in blue) to ensure that the modeler understand how to implement Phase 3. 


\section{Zulkepli and Eldabi}

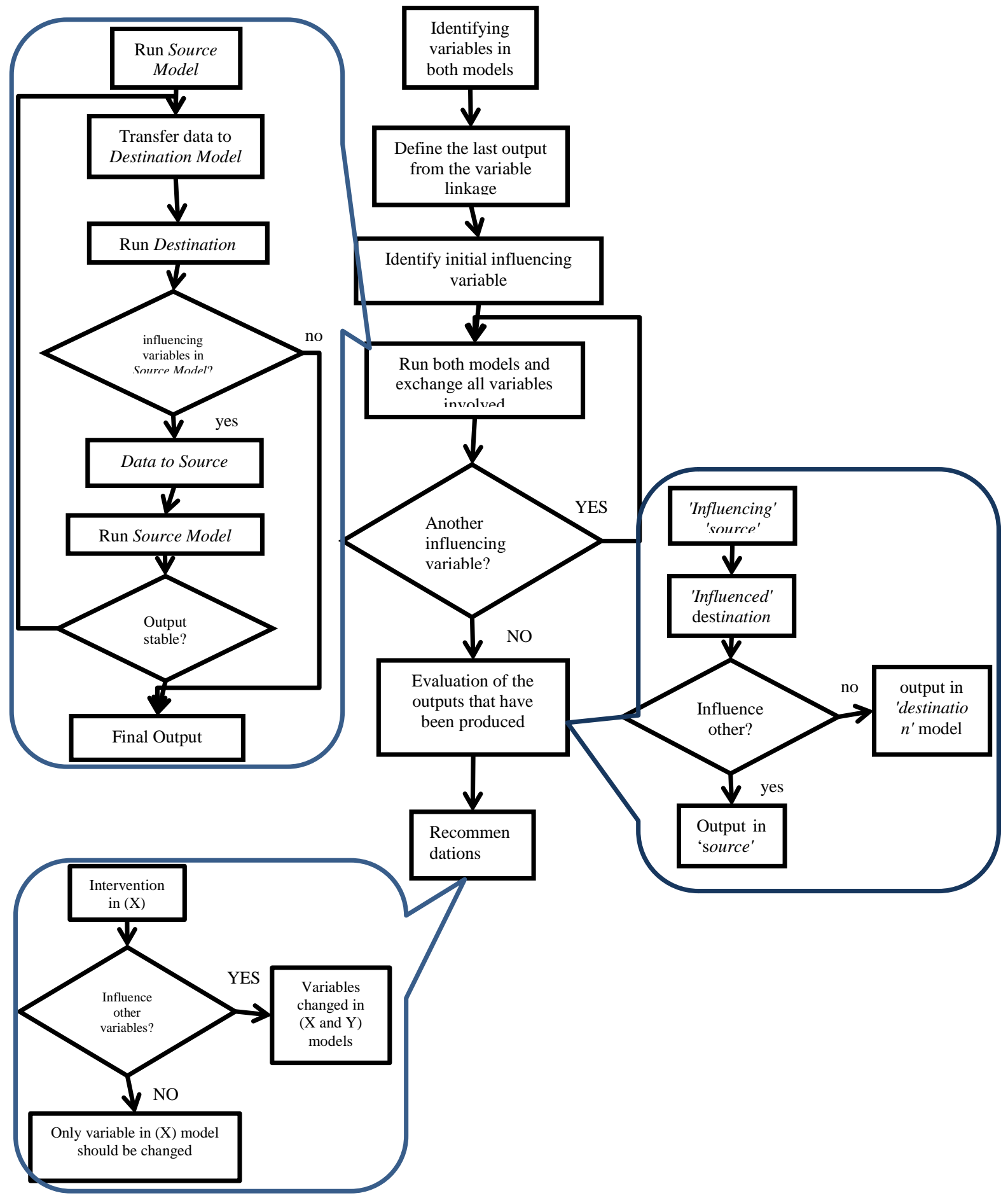

Figure 3: Models communication phase.

\section{DISCUSSION AND CONCLUSIONS}

It is quite challenging to link two models from two different modeling tribes using different commercial, or otherwise, packages. However, such a technical challenge is being overcome and will be completely 


\section{Zulkepli and Eldabi}

resolved in the not so distant future, for example, Anylogic is a software that claims doing just that. On the other hand, linking models conceptually between different techniques is still in its infancy. Most of the hybrid attempts have been following a pragmatic approach to linking models (see Giachetti et al., 2005; Ahmad et al., 2012). The framework proposed in this paper developed purposefully to help non-experts in simulation modeling in healthcare and to allow them to build models using several programming language, such as Anylogic software. The framework also aims to allow modelers to think about some important issues before starting the hybridization process. For example, how both models could be linked using different packages, how to change the information, and how such information will affect the final result from both models. This framework can be considered as an extension to that proposed by Chahal and Eldabi (2008), which was mainly focused on deciding whether to use hybrid modeling or not, by helping in identifying the "hooks" that link between the hybridized models. The framework has been tested to develop complex patient pathways (see Zulkepli 2012; Zulkepli et al., 2012).

Although, we focus on SD and DES in this framework, it is possible to add/substitute these two with other modeling approaches such as Agent Based Modeling and Simulation (ABMS). ABMS is one of the rising modeling techniques that offers extra dimensions when it comes to modeling complex healthcare systems (Macal and North 2010). Another benefit that can be gained from developing this framework is to allow non-technical (from a programming point of view) to think about the hybridization of the logic of the model rather than the code.

\section{REFERENCES}

Ahmad, N., N. A. Ghani, A. A. Kamil, and R. M. Tahar. 2012 "Emergency Department Problem: A Call for Hybrid Simulation". In Proceedings of the World Congress on Engineering 2012 Vol III. London, UK.

Aiken, L. H., S. P. Clarke, and D. M. Sloane. 2002. "Hospital Staffing, Organization, and Quality of Care: Cross-National Findings." Nursing Outlook 50:187-194 .

Aiken, L. H., D. M. Sloane, and J. Sochalski. 1998. "Hospital Organization and Outcomes." Quality in Health Care 7:222-226.

Balaban, M., P. Hester, and S. Diallo. 2014. "Towards a Theory of Multi-Method M\&S Approach: Part I." In Proceedings of the 2014 Winter Simulation Conference, edited by A. Tolk, S. Y. Diallo, I. O. Ryzhov, L. Yilmaz, S. Buckley, and J. A. Miller, 1652-1663. Piscataway, New Jersey: Institute of Electrical and Electronics Engineers, Inc.

Brailsford, S. C. 2008 "System Dynamics: What's in it for Healthcare Simulation Modellers." In Proceedings of the 2008 Winter Simulation Conference, Edited by S. J. Mason, R. R. Hill, L. Monch, O. Rose, T. Jefferson, J. W. Fowler, 1478-1483. Piscataway, New Jersey: Institute of Electrical and Electronics Engineers, Inc.

Brailsford, S. C. 2014. "Modeling Human Behavior: An (ID) Entity Crisis?" In Proceedings of the 2014 Winter Simulation Conference, edited by A. Tolk, S. Y. Diallo, I. O. Ryzhov, L. Yilmaz, S. Buckley, and J. A. Miller, 1539-1548. Piscataway, New Jersey: Institute of Electrical and Electronics Engineers, Inc.

Chahal, K. 2009. "A Generic Framework for Hybrid Simulation in Healthcare." Ph.D. thesis. Brunel Business School, Brunel University London.

Chahal, K., and Eldabi, T. 2008. "Applicability of Hybrid Simulation to Different Modes of Governance in UK Healthcare." In Proceedings of the 2008 Winter Simulation Conference, Edited by S. J. Mason, R. Hill, L. Monch, O. Rose, T. Jefferson, J. W. Fowler, 1478-1483. Piscataway, New Jersey: Institute of Electrical and Electronics Engineers, Inc.

Christie, A. M., and M. J. Staley. 2000. "Organizational and Social Simulation of a Software Requirements Development Process.” Software Process: Improvement and Practice 5(2-3): 103-110. 


\section{Zulkepli and Eldabi}

Dellasega C., D. Orwig, F. Ahern, and E. Lenz. 1999. "Post Discharge Mediation Use of Elderly Cardiac Patients from Urban and Rural Locations." Journal of Gerontology Series a Biological Sciences and Medical Sciences 54:514-520.

Eldabi, T. 1999. "Simulation Modelling: Problem Understanding in Healthcare Management." Ph.D. thesis, Department of Information Systems and Computing, Brunel University London.

Elf, M., and M. Putilova. 2005. "The Care Planning Process - A Case for System Dynamics." In Proceedings of the 25th International Conference of the System Dynamic Society 25:1-18.

Giachetti, R. E., E. A. Centeno, M. A. Centeno, and R. Sundram. 2005. "Assessing the Viability of an Open Access Policy in an Outpatient Clinic: A Discrete Event And Continuous Simulation Modelling Approach." In Proceedings of the 2005 Winter Simulation Conference, edited by M. E. Kuhl, N. M. Steiger, F. B. Armstrong, and J. A. Joines, 2246-2255. Piscataway, New Jersey: Institute of Electrical and Electronics Engineers, Inc.

Helal, M., L., Rabelo, J. Sepúlveda, and A. Jones. 2007. "A Methodology for Integrating and Synchronizing the System Dynamics and Discrete Event Simulation Paradigms." In Proceedings of the 25th International Conference of the System Dynamics Society, edited by J. D. Sterman, M. P. Repenning, R. S. Langer, J. I. Rowe, and J. M. Yarni.3:1-24. Boston, MA System Dynamic Society.

Heywood, J.S. and X. Wei. 2006. "Performance Pay and Job Satisfaction." Journal of Industrial Relations 48:523-540.

James, Jr. H. S. 2005. "Why Did You Do That? An Economic Examination of the Effect of Extrinsic Compensation on Intrinsic Motivation and Performance." Journal of Economic Psychology 26:549- 566.

Lane, D. C. 2000. "You Just Don't Understand: Modes of Failure and Success in the Discourse Between System Dynamics and Discrete Event Simulation." LSE OR Dept Working paper LSEOR 00-34, London School of Economic.

Lee, S.H., S. Han, and F. Peña-Mora. 2007. "Hybrid System Dynamics and Discrete Event Simulation for Construction Management." In Proceedings of the 2007 ASCE International Workshop on Computing in Civil Engineering, edited by L. Soibelman and B. Akinci, 232-239. Reston, Virginia: American Society of Civil Engineers

Macal C. M. and M. J. North. 2010. "Tutorial on Agent-Based Modelling and Simulation." Journal of Simulation 4:151-162.

Martin, R. H. and D. Raffo. 2000. "A Model of the Software Development Process using both Continuous and Discrete Models." Software Process: Improvement and Practice 5:147-157.

McCausland, W. D., K. Pouliakas, and I. Theodossiou. 2005. "Some are Punished and Some are Rewarded: a Study of the Impact of Performance Pay on Job Satisfaction." International Journal of Manpower 26:636-659.

Mingers, J., and J. Brocklesby. 1997. "Multimethodology: Towards a Framework for Mixing Methodologies." Omega 25:489-509.

Pfeffer, J., and N. Langton. 1993. "The Effect of Wage Dispersion on Satisfaction, Productivity and Working Collaboratively: Evidence from the College and University Faculty." Administrative Science Quaterly 38:382-407.

Pressman, R. S. 1997. Software Engineering: A Practitioner's Approach 4th ed. Singapore, McGraw Hill.

Rabelo, L., M. Helal, A Jones, and H. S. Min. 2005. "Enterprise Simulation: A Hybrid System Approach." International Journal of Computer Integrated Manufacturing 18:498-508.

Rabelo, L., M. Helal, Y. J. Son, A. Jones, J. Min, and A. Deshmukh. 2003. "New Manufacturing Modeling Methodology: A Hybrid Approach to Manufacturing Enterprise Simulation." In Proceedings of the 2003 Winter Simulation Conference, edited by S. Chick, P. J. 
Sánchez, D. Ferrin, and D. J. Morrice, 1125-1133. Piscataway, New Jersey: Institute of Electrical and Electronics Engineers, Inc.

Reiner, G. 2005. "Customer-Oriented Improvement and Evaluation of Supply Chain Processes Supported by Simulation Models." International Journal of Production Economics 96:381-395.

Setamanit, S., W. Wakeland, and D. Raffo. 2007. "Using Simulation to Evaluate Global Software Development Task Allocation Strategies. Software Process: Improvement and Practice 12:491-503.

Sweester, A. 1999, "A Comparison of System Dynamics and Discrete Event Simulation." In Proceedings of International Conference of System Dynamics Society and 5th Australian and New Zealand Systems Conference 1999.

Ulrich, R. S. 1991. "Effects of Health Facility Interior Design on Wellness: Theory and Scientific Research." Journal of Health Care Design 3:97-109.

Venkateswaran, J., Y. J. Son, A. T. Jones, and H. S. J. Min. 2006. "A Hybrid Simulation Approach to Planning in a VMI Supply Chain." International Journal of Simulation and Process Modelling 2: $133-149$.

Viana, J. 2014. "Reflections on Two Approaches to Hybrid Simulation in Healthcare." In Proceedings of the 2014 Winter Simulation Conference, edited by A. Tolk, S. Y. Diallo, I. O. Ryzhov, L. Yilmaz, Buckley, and J. A. Miller, 1585-1596. Piscataway, New Jersey: Institute of Electrical and Electronics Engineers, Inc.

Viana, J., Brailsford, S. C., Harindra, V., Harper, P. R. 2014. "Combining Discrete-Event Simulation and System Dynamics in a Healthcare Setting: A Composite Model for Chlamydia Infection." European Journal of Operational Research 237.1: 196-206

Robinson, S. 2008. "Conceptual Modeling for Simulation Part 1: Definition and Requirements". Journal of the Operational Research Society 59(3): 278- 290.

Zulkepli, J. 2012. "A Theoretical Framework for Hybrid Simulation in Modelling Complex Patient Pathways." Ph.D. thesis, Brunel Business School, Brunel University London.

Zulkepli, J. and Eldabi, T. 2011. "Technique for Improving Care Integration Model." In European, Mediterranean \& Middle Eastern Conference on Information Systems 2011 (EMCIS 2011), May 30 31, 2011, Athens, Greece.

Zulkepli, J., Eldabi, T., and Mustafee, N. 2012. "Hybrid Simulation for Modelling Large Systems: An Example of Integrated Care Model." In Proceedings of the 2012 Winter Simulation Conference, edited by C Laroque, J Himmelspach, R Pasupathy, O Rose, AM Uhrmacher, 758-769. Piscataway, New Jersey: Institute of Electrical and Electronics Engineers, Inc.

\section{AUTHOR BIOGRAPHIES}

JAFRI ZULKEPLI is a senior lecturer in Decision Sciences Department in the School of Quantitative Sciences, Universiti Utara Malaysia. He has Bachelor of Information Technology, M.Sc. in Information Technology (Management) and obtained his Ph.D. from Brunel University, UK. His research is into aspects of information technology, Decision Support System, modeling and hybrid simulation, specifically, Discrete Event Simulation and System Dynamics. His email address is zhjafri@uum.edu.my.

TILLAL ELDABI is a senior lecturer at Brunel University. He has B.Sc.in Econometrics and M.Sc. and Ph.D. in Simulation Modeling in Healthcare. His research is into aspects of healthcare modeling and simulation. He developed a number of models and bespoke packages to support health economists and clinicians to decide on best treatment programs. Dr Eldabi has published widely in the field of modeling in healthcare and edited a number of special issues in highly respected journals. Dr. Eldabi's email address is tillal.eldabi@brunel.ac.uk. 